DOI: 10.14526/2070-4798-2020-15-1-15-23

\title{
Comparative analysis of technical actions in students-badminton players taking into account temperament and heart rate indices monitoring
}

\author{
Yuliya K. Zhestkova, Ilsiyar Sh. Mutaeva *, Svetlana R. Sharifullina \\ Yelabuga Institute (branch) of the Kazan (Volga Region) Federal University \\ Yelabuga, Russia \\ ORCID: oooo-ooo3-7622, zhest.13@list.ru \\ ORCID: oooo-0oo2-9387-7033, mutaeva-i@mail.ru* \\ ORCID: oooo-ooo3-4569-2525, radlana@mail.ru
}

\begin{abstract}
Students' sports life is characterized by participation in physical culture and sport events of different orientation and level. First of all it is going in for different sports sections. Badminton as a kind of physical culture and sport activity has become the part of students' life. Modern level of students' badminton development is characterized by badminton players' sufficient technical-tactical readiness and high level of physical qualities. At the same time, there is lack of psychic state self-regulation and psychic readiness control in competitive activity of students-badminton players. In this terms the problem of planning training in studentsbadminton players, taking into account temperament characteristics is reasonable enough. The aim of the research is to realize comparative analysis of badminton players' technical actions taking into account temperament characteristics and heart rate indices monitoring. Materials and research methods. Students-badminton players from Yelabuga Institute (branch) of the Kazan (Volga Region) Federal University (Yelabuga, Russia) took part in the research. The research was held since 2015 till 2019. In order to define the characteristics of students' temperament (among those, who go in for badminton) we used the methodology of professor H.J. Eysenck EPQ (Eysenck Personality Questionnaire). Results. We studied the characteristics of temperament in students, who go in or badminton. We revealed the demonstration of all types of temperament, but most of all there are students-badminton players who belong to the groups of choleric $(46,9 \%)$ and sanguine persons $(34,4 \%)$. In students' badminton team the number of choleric persons prevails, then go sanguine persons. Melancholic and phlegmatic persons are not often revealed. Studying the range of the players temperament characteristics together with their individual style of playing would help to model the process of psychological training, where the inclination for the attacking actions, for the arsenal of technical and tactical actions use, courage, inclination for risk, quickness of reactions and accuracy are taken into account. It was mentioned that "choleric" badminton players fulfill more technical actions during the game 193 striking movements. Choleric persons mainly use below strikes and straight strikes. They demand quickness of reaction. "Sanguine" type people have 161 striking actions during the game, which is 32 times less than among choleric persons. Sanguine persons have lower tempo of movements, than choleric persons. Melancholic persons have 120 striking movements during the game, phlegmatic persons- 90. HR indices among badminton players differ depending on the type of temperament. Choleric persons had high degree of tension during the control period of HR monitoring. Maximum HR index in choleric persons also was high. In order to define fatiguability of badminton players it is necessary to take into consideration the period of HR renewal till maximum values. In sanguine persons HR reaction to the loads in the studied game period is less than in choleric persons. In melancholic and phlegmatic persons HR reaction was less, than in choleric and sanguine persons. Conclusion. The presented results of the held research help to choose the most effective techniques for badminton players taking in to account the types of temperament. They help to change the characteristics of motor activity depending on the type of badminton players' temperament, to carry out physical, functional and psychological training individualization taking into account the type of temperament, increase playing activity of badminton players, select the means of psychic state regulation for fatiguability control during the game, estimate game situations, the volume and intensity of physical loads taking into consideration the type of players' temperament, define the ratio of HR increase time and decrease in different game periods for individual competitive activity tolerance determination by each badminton player, estimate the state of psychic readiness for competitive activity.
\end{abstract}

Keywords: sports training, students-badminton players, type of temperament, technical actions, strikes, heart rate. 
For citation: Yuliya K. Zhestkova, Ilsiyar Sh. Mutaeva*, Svetlana R. Sharifullina. Comparative analysis of technical actions among students-badminton players taking into account temperament and heart rate indices monitoring. Russian Journal of Physical Education and Sport. 2020; 15(1): 14-20. DOI: 10.14526/2070-4798-2020-15-1-15-23

\section{INTRODUCTION}

Badminton is one of the most ancient kinds of physical culture and sport activity. It originated from Indian games. Modern badminton is a unique kind of motor activity. In Russia it became popular among students.

Since badminton was included into the program of the Olympic Games it developed in this country. We can mention high level of technicaltactical actions among badminton players at the International level, success is underlined by confidence of highly-qualified athletes competitive activity. Among students-badminton players there are successful physically and technically players, but it doesn't give them effectiveness in competitive activity. Modern badminton demands quickness of reaction, accurate movements, noise immunity and technical-tactical mastery steadiness of an athletebadminton player [2,3]. All mentioned above factors define the effectiveness of competitive activity among athletes-badminton players.

In this connection modern student's badminton demands not only physical, technical and tactical readiness level increase, but also functional and psychological readiness improvement.

In the sources of recent years specialists pay special attention to psychological readiness in sports games $[6,7,8]$. It is connected with the effectiveness increase of control over psychic state of team members. It provides success of a player's activity in competitive activity [7, p. 96-101].

Scientific-methodical and special literature analysis concerning the problem of training athletes in sports games of different level showed that in order to increase the effectiveness of training it is necessary to consider thoroughly psychological training of players $[4,5,6]$.

First of all, effectiveness of training is connected with students' motivation increase to systematic sport. Students may have initial desire, but the absence of motivation can lead to training lessons attendance. Secondly, badminton demands the team of like-minded people, who correspond with each other according to psychological status.

Many scientists are interested in different sides of sports training. For example, V.A. Alatortsev (2009) studies the state of psychic readiness as the basis of competitive activity effectiveness increase in athletes [1].

O.V.Zhabanov $(1994,1995)$ pays attention to training process control on the basis of comparative analysis of technical mastery among athletes and influences the tempo of game and the effectiveness if functional abilities of badminton players increase $[2,3]$.

In the works of D.R. Zakirov $(2012,2013)$ in order to increase the effectiveness of sports training the psychic readiness state of wrestlers was examined at different stages of training. The methodology of training athletes was created on the basis of taking into account individual characteristics of psych. The importance of the methodology was in the fact that it was demanded in all kinds of sport $[5,6]$.

G.A. Kamalieva (2010) offered the system of difficulties overcoming in training volleyball players using specially created objectives [6].

A.V. Pushkarev (2019) describes the necessity to organize sports training in basketball taking into account functional state and the typology of players according to psychological status as the base for effective team community. These points of view are supported by other authors [7,p.95-101, 9].

Nowadays it is especially important that in student's sport there is teams creation for competitive activity effectiveness increase, taking into account individual peculiarities of the organism.

The aim of the research work was comparative analysis of badminton players' technical actions taking into account their temperament and heart rate indices monitoring.

\section{MATERIALS AND METHODS}

Students-badminton players from Yelabuga Institute (branch) of the Kazan (Volga Region) Federal University (Yelabuga, Russia) took part in the research. The research was held since 2015 
till 2019. In order to define the characteristics of students' temperament (among those, who go in for badminton) we used the methodology of professor H.J. Eysenck EPQ (Eysenck Personality Questionnaire). The last variant of $\mathrm{H}$. J . Eysenck Personality Questionnaire (1970-1980) EPQ is demanded nowadays in order to define the characteristics of athletes' temperament. This method is considered valid and convenient.

Specialists think that the presented variant of H.J. Eysenck questionnaire is suitable for the athletes. The following characteristics of the personality are taken into consideration: confidence, risk level, independence, determination and aggressiveness. Technical actions of badminton players were studied with the help of the game video (CANON MV700), shots handling was realized on the computer using Media Player Classic program. We realized the analysis of the games videos in order to reveal the number of the fulfilled by students technical actions. We realized expert estimation of technical actions among studentsbadminton players with the help of competent experts ( 3 people). In order to analyze the striking actions of badminton players in terms of 9 elements we realized the analysis of general number of their striking actions.

\section{RESULTS AND DISCUSSION}

Table 1 presents the results of studying the characteristics of temperament in studentsbadminton players during five years according to H.J. Eysenck methodology.

Table 1 - The indices of studying the features of temperament in students-badminton players during the following period 2015-2019

\begin{tabular}{|c|c|c|c|c|}
\hline \multirow{2}{*}{ Stages of the research } & \multicolumn{4}{|c|}{ Types of temperament of badminton players } \\
\cline { 2 - 5 } & Choleric & Sanguine & Melancholic & Phlegmatic \\
\hline $2015(\mathrm{n}=8)$ & 4 & 3 & 0 & 1 \\
\hline $2016(\mathrm{n}=15)$ & 8 & 4 & 2 & 1 \\
\hline $2017(\mathrm{n}=13)$ & 4 & 5 & 2 & 2 \\
\hline $2018(\mathrm{n}=14)$ & 7 & 3 & 2 & 1 \\
\hline $2019(\mathrm{n}=14)$ & 7 & 6 & 0 & 7 \\
\hline Total & 30 & 21 & 6 & 2 \\
\hline
\end{tabular}

Table 1 presents the results of studying the persons(34,4\%).

characteristics of temperament among students-

Picture 1 shows the team content within badminton players during 5 years according to H.J. Eysenck methodology. We define all types of temperament among the groups of studentsbadminton players, but most of all they belong to the group of choleric $(46,9 \%)$ and sanguine 5 years taking into account different types of temperament. In student's badminton team choleric persons prevail. The second place take sanguine persons and finally melancholic and phlegmatic persons are not often met.

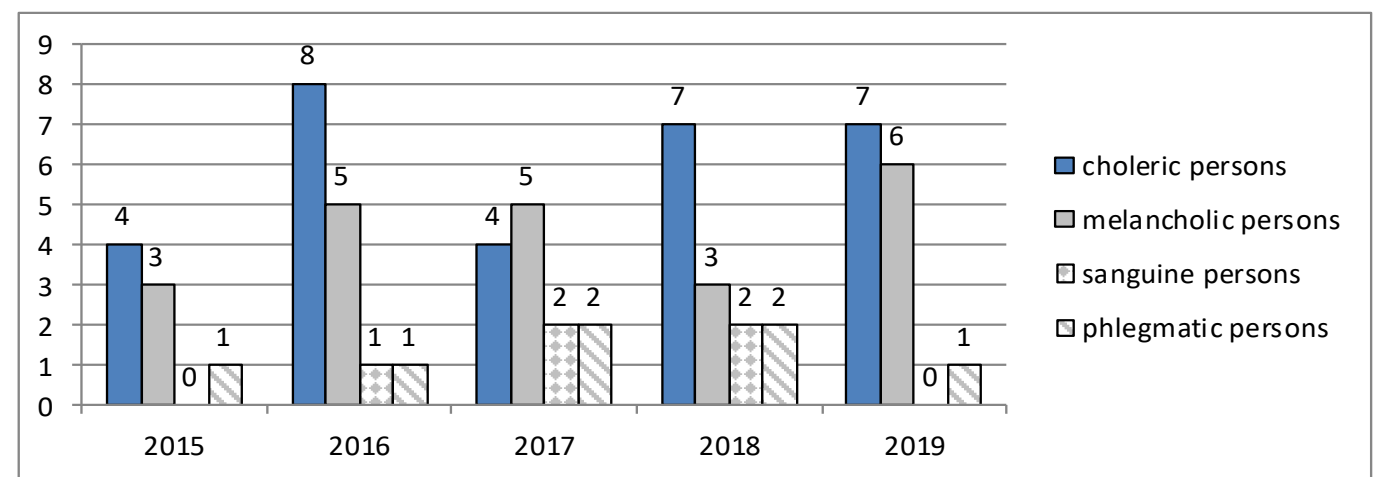

Picture 1 - Dynamics of students-badminton players team content taking into account their types of temperament (number of people) 
Considering and revealing the factors, which influence the success of competitive activity in badminton players, we can't but say about an individual style of game organization. It is characterized by perfect technical means mastering, the ability to use different actions in extreme game situations, high level of flexibility, stability and efficiency.

Owing to an individual style of the type of temperament a badminton player is able to find unexpected variants of solving situational problems, quickness of reaction demonstration. National badminton teams training taking into consideration the characteristics of players' temperament in competitive activity will help to achieve high sports results.

Studying the characteristics of players' temperament in combination with their individual style of game organization would help to model the process of psychological training. There we take into account the tendency to realize the attacking actions, a wide arsenal of technical and tactical actions, courage, desire to take risks, quickness of reactions, accuracy and quickness.

Table 2 - The number of technical actions in students-badminton players during the game (season 20172018)

\begin{tabular}{|c|c|c|c|c|c|c|c|c|}
\hline \multirow{2}{*}{$\begin{array}{l}\text { Technical actions of } \\
\text { a badminton player }\end{array}$} & \multicolumn{2}{|c|}{ Choleric } & \multicolumn{2}{|c|}{ Sanguine } & \multicolumn{2}{|c|}{ Melancholic } & \multicolumn{2}{|c|}{ Phlegmatic } \\
\hline & $\begin{array}{c}\text { Amount } \\
\text { during } \\
\text { the } \\
\text { game }\end{array}$ & $\begin{array}{c}\text { Relative } \\
\text { density, \% }\end{array}$ & $\begin{array}{c}\text { Amount } \\
\text { during } \\
\text { the game }\end{array}$ & $\begin{array}{c}\text { Relative } \\
\text { density, } \\
\%\end{array}$ & $\begin{array}{c}\text { Amount } \\
\text { during } \\
\text { the } \\
\text { game }\end{array}$ & $\begin{array}{c}\text { Relative } \\
\text { density, } \\
\%\end{array}$ & $\begin{array}{c}\text { Amount } \\
\text { during } \\
\text { the } \\
\text { game }\end{array}$ & $\begin{array}{c}\text { Relative } \\
\text { density, } \\
\%\end{array}$ \\
\hline Right strikes & 25 & 12,95 & 15 & 9,31 & 13 & 10,83 & 10 & 11,11 \\
\hline Left strikes & 27 & 13,98 & 16 & 9,93 & 13 & 10,83 & 8 & 6,66 \\
\hline Above strikes & 29 & 15,02 & 23 & 14,28 & 23 & 19,16 & 15 & 12,5 \\
\hline Below strikes & 30 & 15,54 & 17 & 10,55 & 14 & 11,66 & 8 & 6,66 \\
\hline Flat strikes & 8 & 4,14 & 9 & 5,59 & 7 & 5,83 & 13 & 14,44 \\
\hline
\end{tabular}




\begin{tabular}{|c|c|c|c|c|c|c|c|c|}
\hline Flat-far strikes & 8 & 4,14 & 6 & 3,72 & 9 & 7,5 & 3 & 3,33 \\
\hline High-far strikes & 20 & 10,36 & 29 & 18,01 & 23 & 19,16 & 14 & 11,66 \\
\hline Straight strikes & 27 & 14,00 & 26 & 16,14 & 23 & 19,16 & 17 & 18,9 \\
\hline Short strikes & 19 & 9,84 & 20 & 12,46 & 18 & 15 & 15 & 12,5 \\
\hline $\begin{array}{l}\text { General amount of } \\
\text { strikes }\end{array}$ & 193 & 100 & 161 & 100 & 120 & 100 & 90 & 100 \\
\hline
\end{tabular}

Table 2 shows that badminton players use great number of technical actions. The main motional actions, which are fulfilled by badminton players, are the strikes from different positions. Apart from the main actions there are situational actions. They depend on the opponent's actions and game situations. It is noted that "choleric" type badminton players fulfilled 193 striking movements during the game (the greatest index). Relative density of each strike is presented in table 2.

Among choleric persons below and straight strikes prevail. They demand quickness of reaction. It is mentioned that the representatives of the first type are more active (with prevalence of 50 sets). "Sanguine" type representatives fulfill 161 striking actions during the game. It is 32 times less than in choleric persons. The tempo of movement in sanguine persons is less, than in choleric persons, but is higher, than in the representatives of other psychological types. In melancholic persons the amount of striking movements was 120 strikes and in phlegmatic persons- 90 striking movements.

Striking movements of badminton players are different and change from game to game. The main tendency of striking movements relative density change in badminton players is technical mastery improvement. The number of striking movements in badminton players is connected with the state of psychic readiness in terms of competitive activity depending on the type of temperament.

Important components of badminton players' activity are also ball serves, the tempo of the game.

The competitive game analysis among badminton players showed that the game load has an alternating character. It is difficult to define badminton players' active and passive time of game. Motor activity of badminton players during the game can be different. Motor movements registration among students-badminton players was held visually during the pedagogical observation, marking the trajectory of movements. For this purpose different computer programs can be used, but the most effective way for this purpose we consider hear rate indices monitoring. On the basis of summary HR indices we can define game activity and the intensity of the fulfilled by badminton players physical load.

The effectiveness of technical movements use in badminton players depending on their type of temperament helps to form their necessary psychic state before the competitions. The number of the leading strikes decrease can be the index of activity and game effectiveness. Trademark blows and their timely use during the game are the indices of high level of an individual style. Psychic readiness of any athlete is formed during psychological training. In this connection psychological status study taking into account the characteristics of badminton players' temperament helps to form effective thinking activity, accuracy and speed of thinking increase.

An important component of competitive activity effectiveness improvement, in our opinion, 
is the control over competitive load realization. Pedagogical observations showed that depending on the characteristics of temperament we can define the degree of game tension for the definite badminton player.

Table 3 - HR indices in students-badminton players during the game period of control

\begin{tabular}{|c|c|c|c|c|}
\hline Indices & Choleric & Sanguine & Melancholic & Phlegmatic \\
\hline HR at rest & 68 & 64 & 72 & 72 \\
\hline HR min & 118 & 109 & 100 & 100 \\
\hline HR max & 189 & 178 & 164 & 145 \\
\hline HR av. & 164 & 158 & 147 & 143 \\
\hline V, $\%$ & 7,68 & 8,67 & 5,67 & 8,91 \\
\hline
\end{tabular}

Notes: HR at rest- heart rate; HR min - minimal heart rate; HR max - maximum heart rate; HR av. - the average heart rate; V variation coefficient

Table 3 presents that $\mathrm{HR}$ indices in badminton players differ depending on the type of temperament. Choleric persons had a high level of tension within the control part of HR monitoring. Minimal HR index shows till which index the rehabilitation period lasts at rest. Maximum HR index in choleric persons is also high. In order to define fatiguability among badminton players it is necessary to take into account the period of $\mathrm{HR}$ renewal till minimal values.

Among sanguine persons HR reaction to the loads in the studied game period is less, than among choleric persons. Among melancholic and phlegmatic persons HR reactions were less than among choleric and sanguine persons.

The characteristic of HR increase and decrease in different game parts characterizes individual tolerance of competitive load by each badminton player. The analysis of the studied indices depending on the characteristics of badminton players' temperament helps to create an individual regimen of an effective motor activity during the game.

Express-estimation of competitive activity organization in badminton players taking into account their type of temperament helps to control the state of psychic readiness and correct psychic state.

More correct badminton players' actions estimation helps to see individual characteristics of effective technical-tactical actions depending on the types of their temperament.

The studied indices analysis depending on characteristics of temperament in badminton players showed that valid differences between typical choleric, sanguine persons according to psychic characteristics, typical to each type.

\section{CONCLUSION}

Thus, the presented results of the held research works help to do the following:

- select the most effective technical actions for badminton players taking into account types of temperament;

- change the characteristics of motor activity depending on the type of badminton player's temperament;

- to realize the process of physical, functional and psychological training individualization taking into account the type of temperament;

- to increase game activity of badminton players;

- to select the means of psychic state regulation in badminton players for the control over tiredness during game activity;

- to estimate game situations, the volume and intensity of physical loads taking into account the type of players' temperament;

- to define the ratio of the time of HR increase and decrease in different game parts for an individual tolerance of competitive load determination by each badminton player;

- to reveal the state of psychic readiness for competitive activity in badminton players.

\section{REFERENCES}

1. Alatortsev V.A. Gotounost' sportsmen $k$ sorevnovaniyam: opyt psihologicheskogo issledovaniya [An athlete's readiness for competitions: the experience of psychological research]. Moscow: Physical culture and sport. 2009: 31 [In Russ.]. 
2. Zhbankov O.V. Speed-power readiness control in badminton. Teoriya I praktika fizicheskoj kul'tury = Theory and practice of physical culture. 1994; 8: 22-24 [In Russ., In Engl.].

3. Zhbankov O.V.Speed-power training of badminton player in the context of tempo regimen. Teoriya I praktika fizicheskoj kul'tury = Theory and practice of physical culture. 1995; 3: 46-47 [In Russ., In Engl.].

4. Zakirov D.R. Studying the state of psychic readiness of Greco-Roman style wrestling during different periods of training at the stage of sports improvement. Pedagogiko-psihologicheskie and medico-biologicheskie problem fizicheskoj kul'tury I sporta = Pedagogico-psychological and medico-biological problems of physical culture and sport. 2012; 4(25): 41-50. URL: :http://www. kamgifk.ru/magazin [In Russ., In Engl.].

5. Zakirov D.R., Kuznetsov A.S. Methodology of training Greco-Roman style wrestlers on the basis of individual characteristics of psych. Uchenye zapiski universiteta imeni P.F. Lesgafta. 2013; 01(95): 72-79 [In Russ.].

6. Kamalieva G.A. Modular technology of training athletes for competitive obstacles and difficulties overcoming. Obrazovanie I samorazvitie. 2010; 4: 36-42 [In Russ.].

7. Pushkarev A.V. Training lessons planning of a student's basketball team on the basis of taking into account functional state of their types of temperament. Pedagogiko-psihologicheskie and medico-biologicheskie problem fizicheskoj kul'tury I sporta $=$ Russian Journal of Physical Education and Sport. 2019; 14(3):95-101. DOI: 10.14526/20704798-2019-77-82 [In Russ., In Engl.]

8. Fedotova E.V. Sorevnovatel'naya deyatel'nost' I podgotovka sportsmenov vysokoj kvalifikacii hokkeya na trave [Competitive activity and training athletes of high qualification in field hockey]. Kazan: "LogosCenter". 2007: 368-369 [In Russ.].

9. Kuznetsova Z., Kuznetsov A., Mutaeva I., Khalikov G., Zakharova A. Athletes preparation based on a complex assessment of functional state. In Proceedings of the $3^{\text {rd }}$ International Congress on Sport Sciences Research and Technology support. SCITEPRESS. 2015: 156-160.

10. Keating X.D., Guan J., Pinero J.C., Bridges D.M. A meta-analysis of college students' physical activity behaviors. Journal of American College Health. 2005; 54: 116-126. DOI: 10.3200/ JACH.54.2.116-126.

11. Kim S., Kim J. Mood after various brief exercise and sport modes: Aerobics, hiphop dancing, ice skating, and body conditioning. Perceptual and Motor Skills. 2007; 104: 1265-1270. DOI: 10.2466/PMS.104.3.1265-1270.

12. Morinder G., Mattsson E., Sollander C., Marcus C., Larsson U.E. Six-minute walk test in obese children and adolescents: Reproducibility and validity. Physiotherapy Research International. 2009; 14: 91-104. DOI: 10.1002/pri.428.

13. Murno A.G., Harrington L.C. Betweensession reliability of the star excursion balance test. Physical Therapy in Sport. 2010; 11: 128-132. DOI: 10.1016/j.ptsp.2010.07.002.

\section{Submitted: 07.02.2020}

\section{Author's information:}

Yuliya K. Zhestkova - Senior Lecturer, Yelabuga Institute of the Kazan (Volga Region) Federal University, 42360o, Russia, Yelabuga, Kazanskaya str., House 89, e-mail: zhest.13@list.ru

lsiyar Sh. Mutaeva - Candidate of Biological Sciences, Professor, Yelabuga Institute of the Kazan (Volga Region) Federal University, 4236oo, Russia, Yelabuga, Kazanskaya str., House 89, e-mail: mutaeva-i@mail.ru

Svetlana R. Sharifullina - Candidate of Pedagogics, Associate Professor; Yelabuga Institute of the Kazan (Volga Region) Federal University, 4236oo, Russia, Yelabuga, Kazanskaya str., House 89, e-mail: radianai@mail.ru 